\section{Propofol-based sedation does not increase rate of perforation during colonoscopic procedure}

\author{
Somchai Amornyotin, ${ }^{1}$ \\ Ungkab Prakanrattana, ${ }^{1}$ Udom \\ Kachintorn, ${ }^{2}$ Wiyada Chalayonnavin, ${ }^{1}$ \\ Siriporn Kongphlay' \\ 'Department of Anesthesiology; \\ 2Department of Medicine, Siriraj GI \\ Endoscopy Center, Faculty of Medicine, \\ Siriraj Hospital, Mahidol University, \\ Bangkok, Thailand
}

\section{Abstract}

Sedation-related colonoscopic perforation (CP) has been under much debate. Our aim was to assess and compare the $\mathrm{CP}$ rate during colonoscopy by using sedation with or without propofol adjuvant. All patients who underwent colonoscopic procedure at the WGO Endoscopy Training Center, Siriraj Hospital, Thailand from March 2005 to October 2007 by using the intravenous sedation (IVS) technique were analyzed. The primary outcome was the $\mathrm{CP}$ rate; the secondary outcomes were sedation-related complications and death during and immediately after the procedure. There were 6140 colonoscopies and 1532 flexible sigmoidoscopies during the study period, of which 6122 colonoscopic procedures were performed by using IVS. All of these procedures were categorized into two groups: group A, the IVS technique was propofol-based sedation and group B, the IVS technique was non-propofol-based sedation. After matching the indications of procedure, there were 2022 colonoscopies in group A and 512 colonoscopies in group B. Colonoscopic procedures were performed by staff endoscopists (10.8\%) or residents and fellows (89.2\%). The characteristics of patients and sedative agents used in perforated patients in both groups were not significantly different. In group A, five patients $(0.25 \%)$ suffered from perforation and two of them died. In group $B$, one patient (0.20\%) had CP; the difference was not significant $(\mathrm{P}=0.829)$. Our data showed that colonoscopy under propofol-based sedation did not increase the perforation rate. Serious complications are uncommon.

\section{Introduction}

Colonoscopy is the most common diagnostic and therapeutic tool for colorectal carcinoma and is considered a routine procedure for patients with large bowel symptoms. Although colonoscopy is regarded as a relatively safe procedure, it causes significant morbidity and rarely mortality. The most serious complication of colonoscopy is perforation. ${ }^{1.6}$ The incidence of colonoscopic perforation (CP) could be as low as $0.02 \%$ in diagnostic colonoscopy and as high as $0.6 \%$ in therapeutic colonoscopy. ${ }^{7.8}$ In addition, this procedure is uncomfortable and often causes sharp pain to patients. Controversy in safely using analgesics and sedatives during colonoscopy has always existed. The key concern is on perforation rate between colonoscopy with or without anesthesia.

Since 1974, colonoscopic procedures with sedation and/or anesthesia were thought by some people to be a risk factor for perforation. ${ }^{9}$.

${ }^{12}$ However, a previous report by Kjaergard et al. ${ }^{13}$ concluded that anesthesia administered by experienced staff is harmless and that general anesthesia for colonoscopy did not raise the risk of CP. Additionally, there is controversy regarding the frequency of sedation-related complications of colonoscopies especially for CP. Propofol-based sedation usually tends to deepen the sedation level and mask the earlier signs and symptoms of $\mathrm{CP}$. The purpose of our study was to discover whether there is a difference in the incidence of $\mathrm{CP}$ between patients who received colonoscopy with or without propofolbased sedation.

\section{Materials and Methods}

\section{Patients}

A total of 7672 consecutive patients from the WGO Endoscopy Training Center, Siriraj Hospital, Bangkok, Thailand were eligible for the study. These patients underwent colonosscopies (6140) and flexible sigmoidoscopies (1532) from March 2005 to October 2007. Inclusion criteria were age of $\geq 18$ years and colonoscopic procedures performed using the intravenous sedation (IVS) technique. Exclusion criteria were patients younger than 18 years of age, procedures performed in the intensive care units, procedures performed without sedation, or procedures performed under monitored anesthesia care and general anesthesia.

\section{Study design}

This is a retrospective descriptive study. The primary outcome of the study was the $\mathrm{CP}$ rate during and immediately after the procedure. The secondary outcomes were sedation-related complications during and immediately after the procedure and mortality rate.

\section{Assessment of colonoscopic perforation}

After colonoscopy, all patients were observed
Correspondence: Somchai Amornyotin, Department of Anesthesiology, Faculty of Medicine, Siriraj Hospital, Mahidol University, Bangkok 10700, Thailand.

E-mail: sisam@mahidol.ac.th

Key words: intravenous sedation, propofol, colonoscopy, perforation.

Conflict of interest: the authors report no conflicts of interest.

Received for publication: 30 November 2009.

Revision received: 14 January 2010.

Accepted for publication: 19 January 2010.

This work is licensed under a Creative Commons Attribution 3.0 License (by-nc 3.0).

(C) Copyright S. Amornyotin et al., 2010

Licensee PAGEPress, Italy

Gastroenterology Insights 2010; 2:e4

doi:10.4081/gi.2010.e4

in the recovery room for at least two hours before being discharged to the ward or home. We did not call each patient for a day after the procedure. However, the patients suspected of colonoscopic complications and those who underwent difficult procedures were admitted. In addition, all patients visited their endoscopists on the seventh day postendoscopy. The CP rate in both groups was recorded. Additionally, perforation site, type of endoscopist, and mortality rate in the two groups were assessed.

\section{Sedation-related complications}

All sedation-related complications were recorded. These complications were defined as: hypertension or hypotension (increase or decrease in blood pressure by $20 \%$ from baseline and above or below normal for age); tachycardia or bradycardia (increase or decrease in heart rate by $20 \%$ from baseline and above or below normal for age); any cardiac arrhythmias; hypoxia (oxygen desaturation, $\mathrm{SpO}_{2}$ $<90 \%$ ); airway obstruction.

\section{Statistical analysis}

Results were expressed as mean \pm SD or percentage (\%), when appropriate. Comparisons between groups A and B were made by using $\chi^{2}$ - tests (i.e. for categorical variables), $\chi^{2}$-tests for trend (for ordinal variables), and the twosample independent t-test (for continuous variables). The statistical software package SPSS for Window Version 11 (SPSS Inc., Chicago, IL) was used to analyze the data. All statistical comparisons were made with the two-sided 5\% level of significance. 


\section{Results}

There were 6140 colonoscopies and 1532 flexible sigmoidoscopies during the study period. Of these, 18 patients who underwent colonoscopy by using general anesthesia and monitored anesthesia care techniques were excluded. A total of 6122 colonoscopic procedures were performed by using IVS. All of these procedures were categorized into two groups. In group A, the IVS technique was propofolbased sedation. In group B, the IVS technique was non-propofol based sedation. We matched the indications of procedure between the two groups by the ratio of groups A and B (4:1). After matching, there were 2022 colonoscopies in group A and 512 colonoscopies in group B. Colonoscopic procedures were performed by staff endoscopists (10.8\%) or residents and fellows (89.2\%). Table 1 summarizes the clinical characteristics of the two groups. The mean ages in both groups were similar: $57.7 \pm 15.7$ years in group A and $58.3 \pm 14.5$ years in group $\mathrm{B}(\mathrm{P}=0.573)$. There were no significant differences between the two groups in age, sex, weight, ASA physical status, duration of procedure, or indication for colonoscopy.

For all patients, appropriate monitoring was used. Cardiorespiratory monitoring included continuous electrocardiogram, heart rate, oxygen saturation measurements, and five-minute interval noninvasive blood pressure measurements from a blood pressure cuff device. Endtidal carbon dioxide $\left(\mathrm{CO}_{2}\right)$ monitoring with capnography was not used during sedation. The patients were given supplemental oxygenation via a face mask and sedated by welltrained anesthetic personnel directly supervised by a staff anesthesiologist in the endoscopy room. Anesthetic personnel included residents in anesthesiology and anesthetic nurses who were well trained in the use of the IVS technique and airway management. All sedated patients were sedated to either a moderate (conscious) or deep sedation level, according to guidelines of the American Society of Anesthesiologists ${ }^{14}$ and the American Society of Gastrointestinal Endoscopy. ${ }^{15}$

Table 2 demonstrates the $\mathrm{CP}$ rate, perforation site, endoscopist, and mortality rate. Five patients $(0.25 \%)$ on propofol-based sedation and one patient $(0.20 \%)$ on non-propofol-based sedation had $\mathrm{CP}(\mathrm{P}=0.829)$. The sigmoid colon was the most common perforation site in both groups $(\mathrm{P}=0.624)$. All of the perforations were performed by residents and fellows in both groups, except in one CP patient in the propofol-based group that was performed by a staff endoscopist. All perforations were recognized immediately during colonoscopy. Additionally, all CP patients underwent surgical management. Of these perforations, two deaths occurred in group $\mathrm{A}$ and none in group $\mathrm{B}$
Table 1. Characteristics of patients, duration of sedation, and indications of procedure (mean, SD, and percentage).

\begin{tabular}{lccc} 
& $\begin{array}{c}\text { Group A } \\
(\mathrm{n}=2022)\end{array}$ & $\begin{array}{c}\text { Group B } \\
(\mathrm{n}=512)\end{array}$ & P \\
Age (yr) (mean, SD) & $57.7(15.7)$ & $58.3(14.5)$ & 0.573 \\
Gender (\%) & $812(40.2)$ & $204(39.8)$ & 0.897 \\
Male & $1210(59.8)$ & $308(60.2)$ & \\
Female & $57.2(12.5)$ & $56.5(11.4)$ & \\
Weight (kg) (mean, SD) & & & \\
ASA physical status (\%) & $528(26.1)$ & $132(25.8)$ & 0.984 \\
I & $1120(55.4)$ & $284(55.5)$ & \\
II & $374(18.5)$ & $96(18.7)$ & 0.591 \\
III & $30.8(13.9)$ & $30.6(11.1)$ & 0.481 \\
Duration of procedure (min) & & & \\
$\quad$ (mean, SD) & & & \\
Indication & $611(30.2)$ & $153(29.9)$ & \\
Colorectal cancer & $372(18.4)$ & $97(18.9)$ & \\
Lower gastrointestinal hemorrhage & $172(8.5)$ & $40(7.8)$ & \\
Anemia & $261(12.9)$ & $73(14.3)$ & \\
Abdominal pain & $137(6.8)$ & $34(6.6)$ & \\
Bowel habit change & $109(5.4)$ & $28(5.5)$ & \\
Surveillance & $360(17.8)$ & $87(17.0)$ & \\
Others & & & \\
\hline
\end{tabular}

Group A, propofol based; Group B, non-propofol based.

Table 2. Colonic perforation rate, perforation site, endoscopist, and mortality rate (n, \%).

\begin{tabular}{lccc} 
& $\begin{array}{c}\text { Group A } \\
(\mathrm{n}=2022)\end{array}$ & $\begin{array}{c}\text { Group B } \\
(\mathrm{n}=512)\end{array}$ & P \\
$\begin{array}{lcc}\text { Perforation rate } \\
\text { Perforation site }\end{array}$ & $1(0.20)$ & 0.829 \\
$\quad \begin{array}{l}\text { Sigmoid colon } \\
\text { Hepatic flexure colon }\end{array}$ & $4(80.0)$ & $1(100.0)$ & 0.624 \\
$\begin{array}{l}\text { Endoscopist } \\
\quad \text { Resident and fellow }\end{array}$ & $1(20.0)$ & 0 & \\
$\quad$ Staff & $4(80.0)$ & $1(100.0)$ & 0.829 \\
Mortality rate & $1(20.0)$ & 0 & \\
\hline
\end{tabular}

Group A, propofol based; Group B, non-propofol based.

Table 3. Characteristics of patients and sedative agents used in perforated patients.

\begin{tabular}{|c|c|c|c|}
\hline & $\begin{array}{l}\text { Group A } \\
\text { (5) }\end{array}$ & $\begin{array}{l}\text { Group B } \\
\text { (1) }\end{array}$ & $\mathbf{P}$ \\
\hline Age (yr) (mean, SD; range) & 58.6 (23.1), 36-88 & 83.0 & 0.306 \\
\hline $\begin{array}{l}\text { Gender (\%) } \\
\text { Male } \\
\text { Female }\end{array}$ & $\begin{array}{l}3(60.0) \\
2(40.0)\end{array}$ & $\begin{array}{c}0 \\
1(100.0)\end{array}$ & 0.273 \\
\hline Weight (kg) (mean, SD) & $52.6(11.4), 34-60$ & 40.0 & 0.112 \\
\hline $\begin{array}{l}\text { ASA physical status (\%) } \\
\text { I } \\
\text { II } \\
\text { III }\end{array}$ & $\begin{array}{l}1(20.0) \\
2(40.0) \\
2(40.0)\end{array}$ & $\begin{array}{c}0 \\
0 \\
1(100.0)\end{array}$ & 0.549 \\
\hline $\begin{array}{l}\text { Duration of procedure (min) } \\
\text { (mean, SD; range) }\end{array}$ & 64.0 (20.4), 30-80 & 50.0 & 0.199 \\
\hline $\begin{array}{l}\text { Sedative agents } \\
\text { Propofol (\%, mg/kg) } \\
\text { n; mean (SD) }\end{array}$ & $5(100.0), 5.12(3.17)$ & 0 & \\
\hline $\begin{array}{l}\text { Midazolam (\%, mg/kg) } \\
\text { n; mean (SD) }\end{array}$ & $5(100.0), 0.02(0.00)$ & $1(100.0), 0.04$ & $0.014^{*}$ \\
\hline $\begin{array}{l}\text { Fentanyl (\%, mg/kg) } \\
\mathrm{n} ; \text { mean (SD) }\end{array}$ & $5(100.0), 0.001(0.000)$ & $1(100.0), 0.001$ & 0.741 \\
\hline
\end{tabular}

Group A, propofol based; Group B: non-propofol based. * considered statistically significant. 
$(\mathrm{P}=0.447)$. Table 3 shows the characteristics of patients and the sedative agents used in the perforated patients. Only one patient in the non-propofol-based group had CP. There were no significant differences between the two groups in age, gender, weight, ASA physical status, and duration of procedure. Sedative agents including midazolam and fentanyl were commonly used in both groups. Mean dose of midazolam in group $\mathrm{B}$ was significantly higher than in group $\mathrm{A}(\mathrm{P}=0.014)$. Overall adverse events occurred in 602 patients (29.8\%) in group A and in 118 patients (23.0\%) in group B $(\mathrm{P}<0.001)$. Most of the complications were hemodynamic alterations including hypotension, $28.1 \%$ in group A and $18.2 \%$ in group B; hypertension, none in group $\mathrm{A}$ and $1.8 \%$ in group B; bradycardia, $0.9 \%$ in group A and 2.0\% in group $\mathrm{B}$; and arrhythmia, $0.3 \%$ in group $\mathrm{A}$ and $0.8 \%$ in group B. These alterations were transient and did not require any specific interventions. There were no other procedure-related complications (Table 4).

\section{Discussion}

In our present study, the rate of $\mathrm{CP}$ with or without propofol-based sedation was relatively higher than in our previous report ${ }^{16}$ and other published series $^{1-6}(0.25 \%$ and $0.20 \%$ vs. 0.03 $0.09 \%$ ). One possible explanation of this difference is that the number of colonoscopies has increased markedly over the last few years. The majority of colonoscopic procedures were performed by the residents and fellows. It is also plausible that there are an increasing number of patients receiving IVS during colonoscopy, which may affect the endoscopist's perception of alarming pain experienced by the patients. Additionally, this report considered only colonoscopic procedures. If flexible sigmoidoscopy and colonoscopy done with IVS and other anesthetic techniques were included, the $\mathrm{CP}$ rate in our center was $0.09 \%{ }^{16}$ However, the previous series did not mention the frequently used anesthesia/sedation technique. In our present study, we selectively collected the patients who underwent colonoscopy, not flexible sigmoidoscopy, by using the IVS technique. The result of our study also demonstrated that sedation was correlated to the CP indirectly. Consequently, the results of other studies ${ }^{17-20}$ also confirmed that patients could withstand the colonoscopic procedure without anesthesia/sedation, and the rate of $\mathrm{CP}$ was fairly low with this technique without anesthesia/sedation. Colonoscopy under IVS has become a popular technique. Nevertheless, most patients undergoing endoscopy preferred sedation to relieve pain and anxiety. ${ }^{21-23}$ Sedation itself provides an anxiolytic and amnesia, ${ }^{24,25}$ and reduces cardiovascular stress. ${ }^{26}$ Pain induced by the colonoscopic procedure is multifactorial and

Table 4. Sedation-related complications during and immediately after procedure (n, \%).

\begin{tabular}{lccc} 
& $\begin{array}{c}\text { Group A } \\
(\mathrm{n}=2022)\end{array}$ & $\begin{array}{c}\text { Group B } \\
(\mathrm{n}=512)\end{array}$ & $\mathrm{P}$ \\
Overall & $602(29.8)$ & $118(23.0)$ & $<0.001^{*}$ \\
Cardiovascular-related & $592(29.3)$ & $116(22.7)$ & $<0.001^{*}$ \\
Hypotension & $568(28.1)$ & $93(18.2)$ & \\
Hypertension & 0 & $9(1.8)$ & \\
Bradycardia & $18(0.9)$ & $10(2.0)$ & \\
Arrhythmia & $6(0.3)$ & $4(0.8)$ & 0.760 \\
Respiratory-related & $10(0.5)$ & $2(0.4)$ & \\
Hypoxia (SpO2<90\%) & $10(0.5)$ & $2(0.4)$ & \\
\hline
\end{tabular}

Group A, propofol based; Group B, non-propofol based. *considered statistically significant.

it is not easy for endoscopists to help reduce the pain without using analgesics or sedation. However, sedation during total colonoscopy should not be a substitute for good technique. Herman $^{27}$ demonstrated that $82 \%$ of patients who underwent colonoscopy required no analgesia or sedation. When sedation was necessary, smaller doses of medication were required. Colonoscopy without sedation could be important and useful for teaching the technique in training programs. Consequently, it was safer, less expensive, and allowed easier availability of colonoscopy. The previous study also showed that IVS for colonoscopy administered by experienced staff was harmless, and that general anesthesia for this procedure did not involve an increased risk of $\mathrm{CP}^{28}$ Our results demonstrated that propofol-based sedation does not increase the rate of $\mathrm{CP}$ in comparison to non-propofolbased sedation $(\mathrm{P}=0.829)$. In our hospital, the colonoscopic procedure was performed usually by using the IVS technique. The sedative drugs that we commonly used were propofol, midazolam, and fentanyl. Propofol is a sedative without having an analgesic effect. According to the characteristics of propofol, such as quick onset of action with short-effect duration make it a suitable sedative for gastrointestinal endoscopy. ${ }^{29-31}$ Additionally, it exhibits an inhibitory effect on spontaneous contractile activity and concentration-dependent depression of Ach-induced contraction on human gastric and colonic smooth muscles, although the mechanism is unknown. ${ }^{32}$ Midazolam provides hypnotic, sedative, anxiolytic, amnesic, anticonvulsant, and centrally produced muscle relaxant properties. Fentanyl has a short half-life, potent analgesic effect, and rapid onset of action. Opioid receptors were related to modulation of colonic function; for instance, the 82 -opioid receptor agonist was a potent inhibitor in human colonic circular muscle ${ }^{33}$ and $\mathrm{k}$-opioid receptor agonists cause dose-dependent, attenuated presser and visceromotor responses to colorectal distension. ${ }^{34}$ All these drugs are associated with less spastic colon in the colonoscopy procedure.

With standard patient monitoring during colonoscopy, using non-invasive blood pressure, pulse oximeter, and electrocardiography, seda- tion-related complications can be identified and treated promptly before they become serious. The sedation with or without propofol adjuvant was relatively safe and effective. ${ }^{35}$ Most common sedation-related complications were mild, transient, and easily treated.

Although it continues to be questionable whether a colonoscopy performed by a trainee increases the risk of CP, we cannot assess such a potential factor since the trainee-to-staff endoscopist ratio for all procedures in our study was unknown. Anderson and colleges ${ }^{36}$ reported that there was not a significantly increased risk of CP performed by trainee fellows. Many training centers $^{37.39}$ have recommended that a minimum of 50-100 colonoscopies should be carried out by a trainee to gain endoscopic competency. In our center, the fellows and residents had performed 5-10 colonoscopies prior to the study. Their experiences were minimal. These factors may affect the $\mathrm{CP}$ rate. In our study, perforation at the sigmoid colon accounted for more than $75 \%$ of all CP sites in both groups. This findings was consistent with that of other studies. ${ }^{40,41}$ All perforated patients in the current series underwent surgical management like ours. The choice between conservative and surgical management depends on clinical factors. ${ }^{42}$ The CP rate in our report was rather high, and the mortality rate of our patients was relatively higher than in other series because of our patients' coexisting diseases. Furthermore, respiratory complications frequently occur after major abdominal surgery, particularly in advanced-age patients. Pneumonia was the primary cause of death in our study. There are several limitations in this study. First, inaccurate and incomplete documentation of certain measures, as occurs with many chart reviews, also occurred in this study. Second, although we searched the perforated cases as thoroughly as we could, there still exist cases we might have lost. For instance, the patient might receive emergency surgery by other nearby hospitals. Third, our practice employed only basic monitoring that does not include the use of end-tidal $\mathrm{CO}_{2}$ for ventilation monitoring. Thus, respiratory adverse events may be underestimated. Fourth, our study examined the components for intravenous sedation and did not report on endoscopic findings in 
patients with advanced age. Fifth, minor complications were not included in this study, which might lead to ignorance of the sedation-related complications. Finally, our study, which was a retrospective collection of cases from our data base, looked at all colonoscopic procedures in a given short-time period. Further studies should include a well-designed prospective study with close follow-up of every case receiving the colonoscopic procedure.

In summary, we concluded that propofolbased sedation does not increase a rate of perforation during colonoscopy procedure. All sedations with or without propofol adjuvant are relatively safe and effective when carried out by trained anesthetic personnel with appropriate monitoring. Additionally, colonoscopy is safe when performed by physicians in training. Serious complications are uncommon.

\section{References}

1. Arora G, Mannalithara A, Singh G, et al. Risk of perforation from a colonoscopy in adults: a large population-based study. Gastrointest Endosc 2009;69:654-64.

2. Iqbal CW, Chun YS, Farley DR. Colonoscopic perforations: a retrospective review. J Gastrointest Surg 2005;9:1229-36.

3. Cobb WS, Heniford BT, Sigmon LB, et al. Colonoscopic perforations: incidence, management, and outcomes. Am Surg 2004;70: 750-7.

4. Levin TR, Zhao W, Conell C, et al. Complications of colonoscopy in an integated health care delivery system. Ann Intern Med 2006;145:880-6.

5. Panteris V, Haringsma J, Kuipers EJ. Colonoscopy perforation rate, mechanisms and outcome: from diagnostic to therapeutic colonoscopy. Endoscopy 2009;41:941-51.

6. Rabeneck L, Paszat LF, Hilsden RJ, et al. Bleeding and perforation after outpatient colonoscopy and their risk factors in usual clinical practice. Gastroenterology 2008; 135 : 1899-906.

7. Rathgaber SW, Wick TM. Colonoscopy completion and complication rates in a community gastroenterology practice. Gastrointest Endosc 2006;64:556-62.

8. Taku K, Sano Y, Fu KI, et al. Iatrogenic perforation associated with therapeutic colonoscopy: a multicenter study in Japan. J Gastroenterol Hepatol 2007;22:1409-14.

9. Livstone EM, Cohen GM, Troncale FJ, et al. Diastatic serosal lacerations: an unrecognized complication of colonoscopy. Gastroenterology 1974;67:1245-7.

10. Rogers BH, Silvis SE, Nebel OT, et al. Complications of flexible fiberoptic colonoscopy and polypectomy. Gastrointest Endosc 1975;22:73-7.
11. Koyama Y. Fiberscopic examination of colorectal diseases. Am J Proctol 1974;25: 51-9.

12. Smith LE. Fiberoptic colonoscopy: complications of colonoscopy and polypectomy. Dis Colon Rectum 1976;19:407-12.

13. Kjaergard H, Nordkild P, Geerdsen J, et al. Anaesthesia for colonoscopy. An examination of the anaesthesia as an element of risk at colonoscopy. Acta Anaesthesiol Scand 1986; 30:60-3.

14. American Society of Anesthesiologists: Practice guidelines for sedation and analgesia by nonanesthesiologists. An update report by the ASA Task Force on Sedation and Analgesia by Nonanesthesiologists. Anesthesiology 2002;96:1004-17.

15. Cohen LB, Dellegge MH, Aisenberg J, et al. AGA Institute Review of Endoscopic Sedation. Gastroenterology 2007;133:675701.

16. Lohsiriwat V, Sujarittanakarn S, Akaraviputh T, et al. Colonoscopic perforation: A report from World Gastroenterology Organization endoscopy training center in Thailand. World J Gastroenterol 2008;14:6722-5.

17. Takahashi Y, Tanaka H, Kinjo M, et al. Sedation-free colonoscopy. Dis Colon Rectum 2005;48:855-9.

18. Ristikankare M, Hartikainen J, Heikkinen M, et al. Is routinely given conscious sedation of benefit during colonoscopy? Gastrointest Endosc 1999;49:566-72.

19. Eckardt VF, Kanzler G, Schmitt T, et al. Complications and adverse effects of colonoscopy with selective sedation. Gastrointest Endosc 1999;49:560-5.

20. Thiis-Evensen E, Hoff GS, Sauar J, et al. Patient tolerance of colonoscopy without sedation during screening examination for colorectal polyps. Gastrointest Endosc 2000; 52:606-10.

21. Daneshmend TK, Bell GD, Logan RF. Sedation for upper gastrointestinal endoscopy: results of a nationwide survey. Gut 1991;32: 12-5.

22. Thompson DG, Lennard-Jones JE, Evans SJ, et al. Patients appreciate premedication for endoscopy. Lancet 1980;2:469-70.

23. Amornyotin S, Lertakayamanee N, Wongyingsinn $\mathrm{M}$, et al. The effectiveness of intravenous sedation in diagnostic upper gastrointestinal endoscopy. J Med Assoc Thai 2007;90:301-6.

24. Lazzaroni M, Porro GB. Preparation, premedication and surveillance. Endoscopy 1998;30: 53-60.

25. McCloy R, Nagengast F, Fried M, et al. Conscious sedation for endoscopy. Eur $\mathrm{J}$ Gastroenterol Hepatol 1996;8:1233-40.

26. Diab FH, King PD, Barthel JS, et al. Efficacy and safety of combined meperidine and midazolam for EGD sedation compared with midazolam alone. Am J Gastroenterol 1996;91:1120-5.
27. Herman FN. Avoidance of sedation during total colonoscopy. Dis Colon Rectum 1990; 33:70-2.

28. Kjaergard H, Nordkild P, Geerdsen J, Dyrberg V. Anaesthesia for colonoscopy. An examination of the anaesthesia as an element of risk at colonoscopy. Acta Anaesthesiol Scand 1985;30:60-3.

29. Riphaus A, Gstettenbauer T, Frenz MB, et al. Quality of psychomotor recovery after propofol sedation for routine endoscopy: a randomized and controlled study. Endoscopy 2006; 38:677-83.

30. Sipe BW, Rex DK, Latinovich D, et al. Propofol versus midazolam/meperidine for outpatient colonoscopy: administration by nurses supervised by endoscopists. Gastrointest Endosc 2002;55:815-25.

31. Koshy G, Nair S, Norkus EP, et al. Propofol versus midazolam and meperidine for conscious sedation in GI endoscopy. Am J Gastroenterol 2000;95:1476-9.

32. Lee TL, Ang SB, Dambisya YM, et al. The effect of propofol on human gastric and colonic muscle contractions. Anesth Analg 1999;89:1246-9.

33. Mako E, Ronai AZ, Adam G, et al. Modulation by $\operatorname{GABA}(\mathrm{B})$ and delta opioid receptors of neurally induced responses in isolated guinea-pig taenia coli and human colonic circular muscle. J Physiol Paris 2000;94:135-8.

34. Burton MB, Gebhart GF. Effects of kappa-opioid receptor agonists on responses to colorectal distension in rats with and without acute colonic inflammation. J Pharmacol Exp Ther 1998:285:707-15.

35. Riphaus A, Wehrmann T, Weber B, et al. S3 Guildeline: Sedation for gastrointestinal endoscopy 2008. Endoscopy 2009;41:787-815.

36. Anderson ML, Pasha TM, Leighton JA. Endoscopic perforation of the colon: lessons from a 10-year study. Am J Gastroenterol 2000;95:3418-22.

37. Thomas-Gibson S, Williams CB. Colonoscopy training - new approaches, old problems. Gastrointest Endosc Clin N Am 2005; 15:813-27.

38. Wexner SD, Garbus JE, Singh JJ. A prospective analysis of 13,580 colonoscopies. Reevaluation of credentialing guidelines. Surg Endosc 2001;15:251-61.

39. Balfour TW. Training for colonoscopy. J R Soc Med 2001;94:160-1.

40. Hansen AJ, Tessuer DJ, Anderson ML, et al. Laparoscopic repair of colonoscopic perforations: indications and guidelines. J Gastrointest Surg 2007;11:655-9.

41. Luning TH, Keemers-Gels ME, Barendregt WB, et al. Colonoscopic perforations: a review of 30,366 patients. Surg Endosc 2007;21:944-7.

42. Donckier V, Andre R. Treatment of colon endoscopic perforations. Acta Chir Belg 1993;93:60-2. 